\title{
Psycho-pedagogical training as a mean of forming the occupational stress resistance of future teachers
}

\author{
Halyna Meshko, ${ }^{1, *}$, Oleksandr Meshko², Nadia Drobyk ${ }^{3}$, and Oleksander Mikheienko ${ }^{4}$ \\ ${ }^{1}$ Ternopil Volodymyr Hnatiuk National Pedagogical University, Department of Pedagogy and Education Management, Ternopil, 46000 , \\ Ukraine \\ ${ }^{2}$ Ternopil Volodymyr Hnatiuk National Pedagogical University, Department of Psychology, Ternopil, 46000, Ukraine \\ ${ }^{3}$ Ternopil Volodymyr Hnatiuk National Pedagogical University, Department of General Biology and Methodology of Natural Sciences \\ Teaching, Ternopil, 46000, Ukraine \\ ${ }^{4}$ Sumy State Pedagogical University named after A.S. Makarenko, Department of health, physical therapy, rehabilitation and \\ ergotherapy, Sumy, 40035, Ukraine
}

\begin{abstract}
Peculiarities of psycho-pedagogical training, and its role in the preparation of the future teachers for the preservation and strengthening of occupational health, formation of their professional stress resistance, and harmonization of personality are revealed in the article. Activity of the training group was described, aimed at: formation of skills of productive interaction and constructive overcoming of professional difficulties, formation of strategies of protection against stress, teaching of methods and techniques of self-regulation, formation of sanogenic thinking. Dynamics of psychological indicators of the occupational health of future teachers, who took part in the work of psycho-pedagogical training, was checked. Quantitative and qualitative analysis of the results of diagnostics (research of responses, selfreports of participants of training about their state of health, change of way of life or thinking, ways of interaction with others) was carried out. The effectiveness of psychological and pedagogical training as a means of forming professional stress resistance of future teachers has been proved.
\end{abstract}

\section{Introduction}

Nowadays occupational stress is a serious threat to future teachers' health. The World Health Organization called occupational stress the disease of the 21 st century because this stress is common in any profession and has become a global epidemic. Modern teachers, as the representatives of the stressful profession, need protection. To build the resilience of future teachers at the stage of their professional training has become an effective way to protect them from occupational stress is.

Resistance to stress matters in ensuring the effectiveness and reliability of pedagogical activity. Stress resistance is one characteristic of the individual that means the ability to overcome occupational stress. Stress resistance helps the teacher to protect their personality from disintegration; various disorders create the basis for internal harmony, high efficiency, and determines the state of teachers' occupational health.

The analysis of the sources shows that modern psychological science has a large arsenal of managing stress states techniques, ways of optimizing the functional states of a person, methods of preventing negative emotional states that can be used at the stage of the occupational training of future teachers. There were some attempts made to develop different courses for this reason in some Ukrainian and foreign institutions of higher education: "Psychophysiology of Professional
Activity"; "Psychology of Health"; "Medical Pedagogy"; "Culture of Health"; "Culture of Occupational Health"; "A Healthy Lifestyle"; "Health Saving Pedagogy"; "Prevention of the Occupational Burnout Syndrome among Teachers". In most cases, the developed programs of information-prophylactic and physical-fitness orientation focus on formation of students' healthy lifestyle.

The literature review gives grounds to claim that the research is aimed at preventing stress from teachers. Insufficient attention is paid to shaping the resilience of future teachers. Despite the considerable amount of work on this problem, the ways of its formation by future teachers are still unexplored. Therefore, in the problem's context under study, the question of finding ways and means of forming the professional stress of future teachers is urgent. In the arsenal of such tools, there are different training. Among them, we note: training of development of stress resistance of specialists of socioeconomic professions, developed by G. Dubchak [1]; training "Prevention of professional burnout syndrome among teachers" by T. Zaychikova [2]; training of formation of professional stress resistance of future teachers O. Markovets [3]; training programs for raising the level of professional stress of special educators, by N. Tsybulyak [4] and a group of E. Kiel, U. Heimlich, R. Markowetz, A. Braun and, S. Weib [5], etc. Noteworthy are anti-distress training, anti-burn training,

* Corresponding author: hal-meshko@ukr.net 
and personal-professional training for teachers of the Academy of Innovative Development of Education (the project of the Ministry of Education and Science of Ukraine and the National Academy of Educational Sciences of Ukraine).

The purpose of the article is to reveal the role and test the effectiveness of psychological and pedagogical training as a means of forming the professional stress of future teachers.

\section{Methodology}

\subsection{General background of research}

In the scientific literature, the concepts of "emotional stability", "psychological stability", "stress resistance", "stress tolerance", "frustration tolerance", "resilience," are synonymous terms for stress resistance.

Emotional stability is a characteristic that describes an individual in the process of intensive activity. Scientists call the major components of emotional stability the adequacy of emotional assessment of situations, the conformity of emotional reactions, and the harmony of relationships between all components of activity in emotional conditions. The terms mental stability and psychological stability are treated as synonyms in the scientific literature. Mental resistance is a complex personality feature that combines balance and resilience (stability, persistence). At the heart of frustration tolerance as the ability to counteract life and professional difficulties without loss of psychological adaptation is the ability to assess the real situation and the ability to find the way out. Emotional stability in the scientific literature is interpreted as the ability of the individual to maintain resilience under the influence of external and internal threats without losing pace of development Resilience refers to a dynamic process that implies a positive adaptation in significant problems [6].

Professional stress resistance determines the ability to withstand stress effects, negative factors of the pedagogical activity, stressful situations, ability to find their resources in difficult conditions of professional activity [7]. The process of stress management is determined by the individual capacities (resources) used to realize it, and by behaviour strategies and methods of action in a stressful situation that can be constructive and non-constructive. These factors shape the mechanisms of mental regulation of stress management and characterize the essence of this process [8]. Forming future teachers' stress resilience involves foremost, eliminating potential sources of stress in their inner world.

In our study S. Gremling and B. Auerbach's stressors classification is important [9]: controllable stressors, non-controllable stressors, and identified stressors. While dealing with managed stress factors, training (communication training, behavioural training, and personal development training) is the most appropriate. Dealing with uncontrollable stress factors requires changing the assessment of factors as stressful with the help of rational-emotional means and self-regulation of emotional states. Stress management is managing stress, which comprises three main directions: prevention of stress factors, reduction stress from stressors and organization of the system of elimination of negative consequences [10]. Thus, training of mental selfregulation skills, the constructive overcoming of professional difficulties, methods of analysis, interpretation and realistic assessment of stressful situations, mastering constructive handling strategies, the development of the sanogenic thinking, etc. are essential to developing professional stress resistance.

\subsection{Instruments and procedures}

The psychological and pedagogical training, which we have produced, is a means of forming the professional stress resistance of future teachers. Training as practical psychological work is a means of organizing conditions for self-disclosure of participants of the training and autonomous search for the ways of solving their psychological complications. The training is an effective social and psychological education, where the purpose is the acquisition of cognitive knowledge and many practical skills.

Forty students of the second course of pedagogical specialties (future teachers of geography, biology, and chemistry) of the Ternopil Volodymyr Hnatiuk National Pedagogical University named took part in the training's activity groups.

Psycho-pedagogical training is based on the principles of active socio-psychological training. It is a holistic dynamic system of training exercises. Activities of the training group were aimed at creating an atmosphere of goodwill, trust, safety, and security that facilitates the identification of future teachers' psychological problems. During the training, through interpersonal interaction, there is the disclosure of the personal perspectives of the members of the group and its psycho-correction. We focused on the psychological and pedagogical training, not only one solution of personal psychological problems but also on the disclosure of internal potential of the personality, formation properties and qualities that determine the ability to withstand professional stress.

In creating the training program, we relied on principles, used technologies and exercises from other methods of active social and psychological training. The methodological basis for the development of the training program is the teaching of humanistic psychology on the self-perception and self-actualization of the individual, his adequate personal growth. The rational-emotional approach (A. Ellis) became the theoretical and methodological basis of activity for forming professional stress resistance [11], according to which the central link in occurrence of stress is the subjective assessment, and the theory of psychological stress (R. Lazarus, S. Folkman) [12], according to which the main link that causes the stress response is cognitive assessment, determined by the interaction of personal factors and environmental stimuli.

The program of psycho-pedagogical training covers 10 group sessions with a total volume of 40-50 hours. 
The main tasks of psychological and pedagogical training are aimed at starting the process of development of adequate self-esteem, development of sanogenic thinking, constructive interaction and creation of activate psychological mechanisms of self-regulation. The activities of the training group are aimed at forming stress resistance as the ability to find their resources in difficult situations, developing the ability to recognize their emotional state; formation of positive self-concept and assertive behavior; prevention of undesirable qualities, deformities of personality; teaching the basics of self-regulation of stress states; development of readiness for self-change and self-development in professional activity.

The activity of the training group involves updating the personal and neuro-psychic resources of its members, in particular, active strategies of overcoming behaviour, awareness and reduction of the destructive influence of accentuations and temperament, resolving of intrapersonal conflicts. Future teachers are learning to model behaviour in stressful situations, to understand their emotions, to reduce the height of the situation with the help of game tools, the use of different psychotherapists, to focus on the positive.

Future teachers' participation in the training's workgroup contributes to the knowledge of their strengths and weaknesses, the gradual elimination of the neurotic components of their inner world, the improvement of interaction with other people, the harmonization of the integral qualities of the individual. Training creates conditions for the development of such qualities as flexibility in communication, selfconfidence, reflexivity, tolerance. Psycho-pedagogical training helps to master the psych techniques of subjective self-influence. We should also mention that the system of psychological influences is directed at the development of stress resistance of future teachers, it is not general in its nature, but is created based on the students' characteristics.

The operational aspect of the group process in the training group is structured according to the principles of active social and psychological training. One of the main (basic) methods of training is a group discussion since it is almost always included in all other methods in one or another modification. Also, the training group used such methods of work as role-playing situations, psychodrama, psychological games and exercises, psycho-images, psycho-gymnastics, meditative psychological techniques and exercises-relaxation, parable therapy. Methods of psychological and pedagogical training are presented in our article [13].

Psychological and pedagogical training, as active social and psychological training, is based on the processes of positive disintegration and secondary integration of personal structure. It means that the work of the training group is aimed at the disintegration (weakening) of illusory perceptions, which have been created because of the subjective integration by a member of the group of their behaviour - an integral part of the "psychological protection" system. The entire system of "psychological protection" is associated with the deformation of thinking about one's "I", which is supported by insufficient knowledge and unconscious "belief" in the flawlessness of one's "I". Such positive disintegration makes it possible to uncover the true causes of the disintegration of the subject's personal structure. Under the conditions of active social and psychological training, positive disintegration creates an environment for the emotional and personal rapprochement of a member of the group and the people around him, enhancing his capacity for empathy and understanding. Thus, it opens the way to the creation of a new multilevel integral personality structure at a higher level of psychological development [14].

An important psychological point for psychopedagogical training is to create confidence in the participants that the attitudes can be changed only through constructive changes of their own behavioral emotional-rational experience. Training shapes the settings of self-control, tendencies towards planning and changes in one's own communicative behaviour, lifestyle, and thinking.

In the training's workgroup, the following stages of development were observed: initial, working and final.

The initial stage lasted two sessions. At this stage, we informed the participants about the peculiarities of the training group, its goals, and diagnosed the personal problems of the training participants, revealed the motives for participation in the group, the expected results.

The determination of personal issues was facilitated by the discussion: "Understand yourself - and you'll understand the world and become stronger"; "The trust phone exercise" (the group members asked a trust telephone specialist such questions as "How to increase self-esteem?"; "How to control anger?"; "How to become life-sustaining?"; "How to get rid of excessive anxiety?"; "Can I learn how to manage my emotions?"; "How to learn not only to speak but also to think positively?"; "What to do with the influence of the insult?" etc.). Performing the exercises "Motto"; "Wheel of life"; "Symbol of health" helped participants of the group to enter the process "softly", become more relaxed. The participants of the group did their homework - to perform psycho pictures on the theme "I am real, I am perfect" "I and the group".

The second session was devoted to the empirical measurement of the characteristics of members of the group "I perceive you ..." the primary reflection of my image "Me" in the eyes of other students. When performing this task, one felt emotional tension, stiffness of the group members. Therefore, at the end of the classes, relaxation exercises "Star Screen"; "Strawberry Meadow" were performed.

At the initial stage, the focus was on the knowledge of the other person (the members of the group did the "Interview" exercise with great interest, the essence of which was to plan questions to each member of the group to better know the others, while when performing the "Strengths" exercise by the end of the initial stage, an atmosphere of emotional closeness was felt, trust was created, and disintegration concerning the emotional sphere of students. 
The next, four-session work stage was marked by considerable emotional stress, cognitive disintegration, which was because of deep analysis by the group members of the causes of their problems in dealing with other people, internal discomfort, and anxiety. The tasks envisaged at this stage had to activate the positive potential of future teachers, to strive for constructive personal change, to have a great psychological load. These are: modelling of pedagogical situations and their solution (with elements of dramatization), role-playing game "I am a classroom leader: first acquaintance with a class"; performing exercises aimed at the development of sanogenic thinking ("Flushing"; "Dissolution of the image"); exercises that promote the formation of skills of assertive behaviour ("Decent response"; "Request refusal"); discussions on the topics "Secrets of pedagogical interaction"; "How to resist stress and burnout in pedagogical activity"; "Constructive overcoming difficulties in pedagogical activity"); analysing and reproducing situations that students have cited from their own experiences.

Modeling and analysis of various situations created conditions for testing new forms of communicative behavior, understanding the causes of difficulties in interaction with other people, impaired mental equilibrium, deteriorated state of health. At this stage, students were expanding the "front" of self-discovery and self-understanding, and multilevel positive disintegration was taking place. This is evidenced by the depth of analysis of their behavior and behavior of others, awareness of the causes and difficulties, the quality of performance of psycho pictures, other homework (exercise "Letter to yourself"; "Inventory of defects").

In the third, final stage of development of the training group, positive disintegration is completed by secondary integration. Future teachers strive for self-change, selfcreation. They realized that the process of selfexploration and self-improvement does not end with the completion of training, and participation in training is only a step to a constructive change in their behavior, thinking, and lifestyle.

Each lesson began, like the previous ones, by reading the parable, analysing it, and discussing it ("All external changes in a person begin with a change of thoughts"; "How to discover and develop your inner potential"; "Secrets of the teacher's mental equilibrium"; "Steps to the assertive behaviours"; "Constructive coping strategies"; "Professional careers without stress"; "How not to burn in the flames of the profession"; "Change the thinking-change yourself and your life"; etc.), during which members the groups expressed their thoughts, feelings, doubts. At the class, students exchanged impressions of their previous class, analyzed psychopictures, and performed open sociometry. The members of the group gave each other already full psychological characteristics (games "Thoughts on character"; "Prosecutor and lawyer"; exercise "Suitcase"; "What would you take from another person for yourself, what would you give her, what would you throw away?"). During the exercise "Me, perceived with the eyes of the other members of the group" (lesson 9), each participant expressed his or her ideas about how the group perceives him/her. The group acted as a collective expert, correcting one whose views diverge from the true perception of his group. Participants even made predictions about what could be an obstacle for a group member to work on themselves, a constructive change in themselves (during the game-hot seat psychodrama, lesson 9, a member of the group in the centre of the room with their back to the group, everyone made predictions about what may interfere with work on yourself: "I hope you think about yourself the following...”).

Analysis and introspection of psychopictures "Me and our group"; "What the group gave me"; "My strengths and weaknesses"; "My state before the group, my state after the group"; gave a lot of important information in personal changes of the participants, the ability to identify their value orientations, group dynamics, etc.

As an example, let's observe the self-analysis of Iryna's psycho picture "I am before the group activities, I am after the group activities", performed after the ninth training session: "Before the group I felt like a lonely snowdrop which has just broke out of snow and needs warmth. It is cold and lonely. I am unsure of myself (the snowdrop bends to the ground), timid, very anxious. After group activities, my outlook and perception of me and the others changed. I perceive myself as a colourful flower, warmed by the sun. I see other members of the group with the same multi-coloured colours. I am happy with myself and with them. My state of mind is very pleasant (bright, but, "not flashy" but quiet, harmonious with nature). I'm filled with life. I'm thinking optimistically..."

Psycho pictures on the topic "I am real - I am perfect"; and "I am a real student - an ideal teacher"; were informative. The group members compared themselves to animals, plants, geometric shapes, other images: (real - sunflower seeds, perfect - sunflower; real - unripe wormy apple, perfect - ripe red-sided apple; real - cold, shining, not warm, star perfect - the sun; real - a navel punching through the stones; perfect - a blossoming lush rose; real - a spikelet that ripens in the sun; perfect its baked bread; real - a lonely boat that can't swim to the shore; perfect - a fire, torch; real caterpillar, perfect - butterfly, etc.).

For the formation of sanogenic thinking of future teachers, we used the technique of sanogenic reflection. This method of behavioral correction is based on the change and purification of thinking as the basis of formation of the attitude to a positive attitude to himself and the situation, involves mastering mental operations and introspection skills. The purpose of the method of sanogenic thinking is to desensitize the pathogenic harmful effects of the energy of negative emotions (anger, insults, guilt, feelings of shame, envy, etc.) [15].

We used the teaching method of sanogenic thinking in two aspects: 1) to identify priority habitual stereotypical pathogenic thinking causes deterioration of state of health and health; 2) for the purpose of teaching sanogenic thinking for "healing" of an organism, 
formation of a setting for self-creation, self-development with priority of a health-saving strategy of life.

The technique of forming sanogenic thinking can be called auto-psychoanalysis of emotions, which is a catalyst for the transformation of pathogenic thinking into sanogenic. Auto-psychoanalysis exercises of negative emotions, which were performed by members of the training group, training in positive thoughts, images and feelings helped to merge sanogenic thinking as a priority in much behaviour and activity.

Learning objectives of sanogenic thinking include the mastery of introspection to restore the details, circumstances, situations in which future teachers fixed and "deepened" their auto-destructive behaviour. Introspection in conducting sessions of the training group gives a possibility to separate negative emotional reaction from negative habitual patterns of autodestructive behaviour, which destroy health, to reduce negative emotional response to situational influences. Exercises "Forgiveness"; "Flushing"; "Write the offender unsent letters"; "To caricature the offender"; "A pleasant surprise to their abuser" contribute to the mastering of sanogenic type of thinking, the liberation from age-old grievances and negative emotional states.

The members of the training group performed relaxation exercises aimed at getting rid of negative emotions, relieving emotional stress ("Anti-stress relaxation"; "Stress yourself out of stress"; "Abandoned garden"; "Journey to the bottom of the ocean" etc.). Participants of the training, by mastering and comprehending the negative emotional states that surround them, neutralize their negative emotions, which cause psychological discomfort. Many training members kept diaries in which they recorded self-observation data.

The following methods were used to track the dynamics of the psychological indicators of the occupational health of future teachers who took part in the psycho-pedagogical training: 1) Freiburg personality inventory (FPI) for the diagnosis of the states and characteristics of the personality; 2) the method of "Accumulation of emotional energy charges directed at oneself" to detect the hidden emotional tension of teachers; 3) Questionnaire "The scale of emotional excitability"; 4) C. Spielberger - Y. Hanin questionnaire, designed to assess reactive and personal anxiety; 5) an adapted version of J. Jenkinson's technique for determining stress predisposition) [16-18].

\section{Results}

We analyzed the effectiveness of the tools we had implemented to correct the occupational health of experimental participants. In particular, the effectiveness of psychological and pedagogical training is presented in Table 1 average group of future teachers' occupational health before and after the training.

Indicators, displayed in Table 1, show the level of relevant qualities' formation and the main psychological indicators of occupational health: emotional states (conflict, balance), personal qualities (irritability, depression, anger, spontaneous and reactive aggression, self-management), anxiety self-control, difficulties in assessing situations). The significant changes in these indicators during the training were assessed using the Student's t-criterion.

Table 1. Comparative analysis of the dynamics of psychological indicators of professional health of future teachers (before and after conducting psycho-pedagogical training).

\begin{tabular}{|c|c|c|c|c|}
\hline Methods & Parameters & $\begin{array}{l}\text { Before } \\
\text { the } \\
\text { trai- } \\
\text { ning } \\
\end{array}$ & $\begin{array}{l}\text { After } \\
\text { the } \\
\text { trai- } \\
\text { ning }\end{array}$ & $\begin{array}{c}\text { Stu- } \\
\text { dent's } \\
\text { t- crite- } \\
\text { rion } \\
\end{array}$ \\
\hline \multirow{11}{*}{$\begin{array}{l}\text { Freiburg Per- } \\
\text { sonality Ques- } \\
\text { tionnaire (FPI) } \\
\text { for diagnosing } \\
\text { conditions and } \\
\text { personality } \\
\text { traits }\end{array}$} & I - "neuroticism" & 4,29 & 3,53 & $3,34^{* *}$ \\
\hline & $\begin{array}{l}\text { II - "spontaneous } \\
\text { aggression" }\end{array}$ & 3,09 & 2,44 & $2,57^{*}$ \\
\hline & $\begin{array}{l}\text { III - "depressive- } \\
\text { ness" }\end{array}$ & 3,53 & 2,90 & $2,16^{*}$ \\
\hline & IV - "irritability" & 4,68 & 3,53 & $3,09^{* *}$ \\
\hline & $\mathrm{V}$ - "friendliness" & 8,03 & 8,25 & $-0,95$ \\
\hline & VI - "equilibrium" & 7,09 & 7,75 & $-2,53^{*}$ \\
\hline & $\begin{array}{l}\text { VII - "reactive } \\
\text { aggressiveness" }\end{array}$ & 3,81 & 3,31 & 1,58 \\
\hline & VIII - "shyness" & 7,16 & 6,53 & $2,26^{*}$ \\
\hline & $\begin{array}{l}\mathrm{X} \text { - "extraversion- } \\
\text { introversion" }\end{array}$ & 4,88 & 4,75 & 0,38 \\
\hline & $\begin{array}{l}\text { XI - "emotional } \\
\text { instability" }\end{array}$ & 4,0 & 3,22 & $2,60^{*}$ \\
\hline & $\begin{array}{l}\text { XII - "masculini- } \\
\text { ty-femininity" }\end{array}$ & 3,29 & 2,97 & 1,06 \\
\hline \multirow{2}{*}{$\begin{array}{l}\text { Spielberger- } \\
\text { Hanin Questi- } \\
\text { onnaire }\end{array}$} & Personal anxiety & 37,31 & 33,38 & $3,33^{* *}$ \\
\hline & Reactive Anxiety & 30,78 & 28,0 & $2,13^{*}$ \\
\hline \multirow{4}{*}{$\begin{array}{l}\text { Emotional Ex- } \\
\text { citability Scale } \\
\text { Questionnaire }\end{array}$} & Emotionality & 22,47 & 19,75 & $4,82^{* * *}$ \\
\hline & Anger & 7,41 & 6,43 & $2,06^{*}$ \\
\hline & Timidity & 9,13 & 7,94 & $2.32^{*}$ \\
\hline & $\begin{array}{l}\text { Lack of control } \\
\text { over emotions }\end{array}$ & 6,09 & 4,71 & $2,60^{*}$ \\
\hline $\begin{array}{l}\text { Methodology } \\
\text { "Accumulati- } \\
\text { on of emoti- } \\
\text { onal and ene- } \\
\text { rgy charges } \\
\text { directed at } \\
\text { oneself" }\end{array}$ & $\begin{array}{l}\text { Hidden emotional } \\
\text { tension }\end{array}$ & 15,72 & 13,59 & $3,90^{* * *}$ \\
\hline
\end{tabular}

Notes: asterisks significant differences:

* - significance level 0.95;

** - significance level 0.99;

${ }^{* * *}$ - significance level 0.999 .

The results of the study obtained using the shown in table methods, indicate high rates of neuroticism (anxiety, increased excitability). There are high levels of irritability, which confirm the poor self-regulation of students' mental states, and the level of depression, which is an evidence of a low mood background, immersion in their experiences. Indicators of reactive anxiety of future teachers (prior to participation in the training) show a high level of psychopathization, characterized by painful reaction to criticism and remarks to their address, sometimes manifestations of an aggressive attitude towards the social environment. Low levels of emotional instability and emotionality may be associated with maladaptation, student anxiety, and high levels of frustration. 
The results of the use of the Jenkinson method confirmed a high tendency of future teachers to stress (Figure 1). 3 respondents (7,5\%) showed a low tendency to stress; 22 respondents $(55,0 \%)$ had an average tendency to stress; 5 respondents $(12,5 \%)$ have very high tendency to stress; 7 respondents $(17,5 \%)$ have a high tendency to stress. Three respondents $(7,5 \%)$ scored from 13 to 15 points, i.e. they "fell" in the neutral zone of tendency to stress. After the training, the level of future teachers' stress resilience increased.

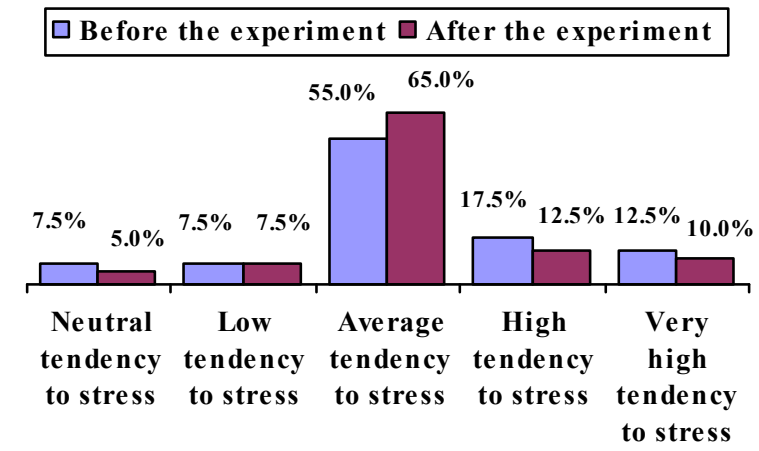

Fig. 1. Distribution of future teachers by level of tendency to stress according to the results of the survey before and after conducting psycho-pedagogical training (in \%).

As a result of conducting a psycho-pedagogical training, there have been significant changes in many psychological indicators of the future teachers' occupational health. To test the statistical significance of these changes we used the indicators of future teachers to compare. As the level of subjective control increases in the process of psycho-corrective influence on the individual, we can use it to test the effectiveness of psychological correction methods. The level of subjective control was calculated as the arithmetic way of the scores obtained on the total internality scale. We took into account the dynamics of the group-level indicators of the level of subjective control of the training participants and the control sample. In particular, it was found that the initial states of both samples are characterized by almost identical indicators of the level of subjective control (the difference between them is only 0.006 points. The results of the final diagnostic slice show a high increase in the average group level of subjective control - 0,781 (+0,375) participants training, whereas this indicator for control groups was only 0,464 points $(+0,05)$, and the difference in achievement by this criterion between control and experimental samples was 0,325 .

To determine how valid the qualitative differences in the group values of the levels of subjective control of participants of training and control sample at the end of the experiment were, we applied the Student's t-test. The empirical value of the $\mathrm{t}$-criterion $(t=3,7)$ was compared with the corresponding table value. For the 5\% significance level in our case, the t-table is $1,9-$ it is much smaller than the empirical value of the t-criterion. Therefore, the differences in the mean values of the level of subjective control of the participants of the training and the control sample at the end of the training are statistically significant. And this confirms the effectiveness of our developed psychological and pedagogical training.

In addition to quantitative analysis of the results of diagnostics, we also carried out their qualitative analysis (research of responses, self-reports of participants of training about their well-being, change of lifestyle or thinking, ways of interacting with others, etc.). The freeform opinions of the trainees provide important material is at least depth, and sometimes more informative, for objective data, limited by diagnostic methods. Here are examples of the following reports:

Sergei: "I learned a lot about myself. There were things I had not realized before. I did not think about the motives of behavior. I realized how important the state of the intellectual-emotional sphere could be for pedagogical activity. The inner tension disappeared (I was especially impressed by the relaxation exercises). Heard a lot of unpleasant information about myself - this is a field for reflection, change of myself. I realized that it was not that easy to forgive, myself and my actions..."

Olga: "I learned to accept myself the way I am. The exercise "Creating ode for the self" helped me a lot. The group opened my eyes - it turns out that I did not know myself well enough, nor did I knew how others perceived me. She became more sincere with people. I want to think and act positively. It is difficult to master the techniques of self-regulation of the inner world, to manage emotions..."

Olesya: "I understood myself and the others better. By understanding ourselves, we can understand others. The group helped me to understand the reasons for the failures, the difficulties in communication. She trusted people became more and more confident. I learned to accept others the way they are. In the group, she experimented with new forms of communicative behavior. There is something to work with. I was aware of this when I was a teacher, a class teacher. It was difficult to restrain yourself, to influence students. I understood what needed to be done in order not to burn in the flames of the profession, to maintain "a good form"..."

The feedback and self-reports of the participants in the training show the positive dynamics of their personal change and are consistent with the results of quantitative analysis of our diagnostic measures. Together, they show significant positive changes to certain experimental indicators that have come about through implementing the tools we have offered to correct the health of the participants.

\section{Discussion}

The results of the experimental study show the effectiveness of the developed psycho-pedagogical training and the expediency of its introduction into the educational process of higher education institutions for preparing future teachers for the preservation and strengthening of the professional health, formation of the professional stress resistance. 
Using psycho-pedagogical training in working with prospective teachers contributes to understand their strengths and weaknesses, identification and change of those traits and behaviours that trigger and support emotional stress (irritability, envy, shyness, vanity, morbid vanity, lack of self-esteem, anxiety, ambition, vindictiveness), the gradual elimination of the neurotic components of their inner world, improvement of interaction with others, coordination of the integral qualities of the person. Psychological intervention work was aimed at elimination or mitigation of such negative manifestations in the teacher's personality as shyness, irritability, aggression, neurotic, depression, affect low resistance to occupational stress. Because of participation in the work of psychological and pedagogical training, the basic psychological indicators of the professional health of future teachers were changed: emotional states (conflict, equilibrium), personal qualities (neuroticism, irritability, depression, anger, spontaneous aggressiveness) and self-regulation of emotional state).

Future teachers, who took part in the work of psychological and pedagogical training, show an increase in the stress resistance level, assertive behaviour, and possession of constructive coping strategies.

\section{Conclusions}

Teacher's profession is stressogenic, tensed in the psychological terms. An effective way of protection against occupational stress is building up stress resistance at the professional training stage. It is one of the personality traits that ensure that professional stress can be overcome.

Professional stress is interpreted as the ability to withstand stress, negative factors of the pedagogical activity, stressful situations, and the ability to find their own resources in difficult conditions of professional activity. Forming stress resilience for future teachers is associated with finding resources that help overcome the negative effects of stressful situations and eliminate potential sources of stress in their inner world.

An effective means of forming future teachers' professional resilience is the psycho-pedagogical training, which we have developed, is built on the principles of active social and psychological training. The activities of the training group are aimed at the formation of skills of productive interaction and constructive conflict resolution and overcoming the professional difficulties, formation of strategies for protection against stress, teaching methods, and techniques of self-regulation, the formation of sanogenic thinking. Participation in the training group facilitated the mobilization of the personal and neuro-psychic resources of future teachers, and acquisition of subjective self-influence by psychologists.

The dynamics of psychological indicators of the occupational health of future teachers, who took part in the work of psycho-pedagogical training, turned out to be positive and the significant changes were traced.
We see the prospects of further scientific exploration in identifying the possibilities of psychological and pedagogical training in preventing the professional deformations and destructive changes in the teacher's personality in the system of postgraduate pedagogical education.

\section{References}

1. G.M. Dubchak, Psykholohichni osnovy profesiinoi stresostiikosti maibutnikh fakhivtsiv (Psychological bases of professional stress resistance of future specialists). (Talkom, Kyiv, 2017)

2. T.V. Zaichikova, Visnyk of NTUU "KPI". Philosophy. Psychology. Pedagogics 3(24), 135-137 (2008)

3. O.L. Markovets, Scientific Issues: Collection of scientific works National Pedagogical Dragomanov University. Pedagogical, Historical and Physicalmathematical Sciences, 52, 90-94 (2003)

4. N.Yu. Tsybulyak, Scientific Bulletin of Kherson State University. Series "Psychological Sciences" 4, 266-274 (2019)

5. E. Kiel, U. Heimlich, R. Markowetz, A. Braun, S. Weib, European Journal of Special Needs Education 31(2), 421-429 (2016)

6. D. Fletcher, M. Sarkar, European Psychologist 18, 12-23 (2013)

7. M. Babych (ed.), Modern World tendencies in the development of science, vol. 2, (Sciemcee, London, 2019), pp. 58-72

8. V.A. Bodrov, Psihologiya professionalnoy deyatelnosti. Teoreticheskie i prikladnyie problemy (Psychology of professional activity. Theoretical and applied problems). (Institut psihologii RAN, Moscow, 2006)

9. S. Gremling, B. Auerbach, Praktikum po upravleniyu stressom (Workshop on stress management). (Piter, Saint Petersburg, 2002)

10. M.V. Fedorenko, Stress-menedzhment v professional'noj dejatel'nosti pedagoga (Stress management in teacher's professional activity). (KGU, Kazan, 2016)

11. A. Ellis, Current Psychotherapies (Peacock, Itasca, 1989)

12. R. Lazarus, S. Folkman, Dynamics of stress Physiological psychological and social perspectives (New York, 1986)

13. H. Meshko, IJSEIro 3(5), 85-92 (2016)

14. T.S. Yatsenko, Aktivnaya sotsialnopsihologicheskaya podgotovka pedagoga $k$ obscheniyu s uchaschimisya (Active socialpsychological preparation of the teacher for communication with students). (Osvita, Kyiv, 1993)

15. T.N. Gorobec, Osnovyi korrektsionnoy akmeologii (Basics of corrective acmeology). (RAGS, Moscow, 2007) 
16. M.S. Korolchuk, V.M. Krainiuk, Socialjnopsykhologhichne zabezpechennja dijaljnosti $v$ zvychajnykh ta ekstremaljnykh umovakh (Sociopsychological support of activities in ordinary and extreme conditions). (Nika-Tsentr, Kyiv, 2006)

17. E.I. Illin, Emotsii $i$ chuvstva (Emotions and feelings). (Piter, Saint Petersburg, 2001)

18. B.A. Smirnov, E.V. Dovgopolova, Psihologiya deyatelnosti $v$ ekstremalnyih situatsiyah (Psychology of activity in extreme situations). (Gumanitarnyj centr, Kharkiv, 2007) 